\title{
KNOWLEDGE ON HEALTH EFFECTS AND PRACTICES OF SMOKING AMONG THE SMOKERS IN EASTERN TERAI REGION OF NEPAL
}

\author{
S Uprety ${ }^{1 *}$, IS Poudel ${ }^{1}, \mathrm{~S}$ Bhattarai ${ }^{1}$, A Ghimire ${ }^{1}, \mathrm{~N}$ Singh ${ }^{2}$, M Poudel ${ }^{3}$, RB Rayamajhi ${ }^{1}$, PK Pokharel ${ }^{1}$ \\ ${ }^{1}$ School of Public Health and Community Medicine, BP Koirala Institute of Health Sciences, Dharan, Nepal. \\ ${ }^{2}$ Departments of Community Medicine, Kist Medical College and Teaching Hospital, Imadol, Kathmandu, Nepal. \\ ${ }^{3}$ Department of General practices and Emergency Medicine, BP Koirala Institute of Health Sciences, Dharan, Nepal.
}

*Correspondence to: Dr Samyog Uprety, School of Public Health and Community Medicin, B. P. Koirala Institute of Health Sciences, Dharan, Nepal. Email: samyoguprety@gmail.com

\begin{abstract}
Tobacco smoking kills more than five million people a year worldwide. According to Nepal Adolescent and Young Adult (NAYA) Survey 2000, about one quarter of young boys and one in 10 girls have smoked tobacco at some time or the other. A cross sectional study was done in Jalthal \& Maheshpur Village Development Committee of Jhapa district using simple random sampling method among 200 participants. Interview methods with semi-structured questionnaires were used as tool for data collection. The objective of this study was to identify the reason of initiation of smoking, explore the pattern of smoking and to assess the health knowledge among the smokers regarding effect of smoking. It was reported that, $63 \%$ of them started to smoke at the age of 10-19years.Most smokers were male, illiterate, unemployed and fell below the poverty line. Though most of the smokers knew the ill effect due to smoking; habituation was the main reason for not being able to stop smoking and $10 \%$ of them smoked for recreation.
\end{abstract}

Key Words: Filter, Foul smell, Smokers.

\section{INTRODUCTION}

The World Health Organization estimates that approximately 5 million people die each year worldwide from tobacco related illnesses. If current trend continues, this figure will rise to about 10 million per year by $2025 .{ }^{1}$ Worldwide approximately 1.3 billion people smoke cigarettes or other tobacco related products. Almost one billion men and 250 million women. ${ }^{2}$ Globally, tobacco use is significantly higher among men (47\%) than women $(12 \%){ }^{3}$ In developing countries $50 \%$ of the men and $9 \%$ of the women are smokers. ${ }^{4}$ In most developing countries, this is partly due to culture and traditions but the situation is changing and more women are taking up smoking in response to the marketing tactics of the tobacco industry. ${ }^{5}$ By 2030, a projected 7 million people in developing countries will be killed every year by tobacco or tobacco related products. ${ }^{4}$

In Nepal, proportional mortality from chronic non-communicable diseases (NCDs) is $42 \% .^{7}$ Such high mortality may be due to high smoking rates in the population aged 18 years and above. ${ }^{8}$ The prevalence rate of tobacco use from small scale surveys ranges from $20 \%$ of $72 \%$ among different population groups. ${ }^{9-12}$ The main form of tobacco consumption in Nepal is cigarettes; though other type of smoking tobacco i.e., 'bidis' (hand-rolled cigarettes that contain unprocessed tobacco) are also common. ${ }^{13}$

The purpose of the study is to identify the reason for initiation of smoking, explore the pattern of smoking and to assess the health knowledge regarding effect of smoking among smokers.
This study will help us to formulate and plan necessary smoking cessation programmers for smokers and aid in raising the awareness programmes regarding ill health consequences of smoking among smokers and the population at risk.

\section{MATERIALS AND METHODS}

This descriptive cross sectional study was done in Jalthal \& Maheshpur VDCs of Jhapa district. VDC was selected purposively and the samples were selected randomly till the sample size reached 200. Semi-structured questionnaires were used as tool for data collection. Both open and close ended questionnaire were used to assess the knowledge, attitude and practices of smoking among the smokers. Inclusion criteria were all the current smokers regardless of age and gender smoking for more than one year. The subjects who had already quitted smoking for more than one year, alcohol consumer, chewing tobacco and not willing to participate in study were excluded. The operational definition used in this study is explained below. ${ }^{14}$

a) Never Smoker: Someone who never smoked cigarettes (not even a puff) in his/her life time.

b) Ever smoker: Someone who had ever tried one cigarette or less in life time.

c) Currently Smoker: The smoker who smoked cigarette one or more in the past 30 days prior to the survey.

CAGE criteria were used to check the dependency status of the 
smokers. CAGE criteria include four questions and declare the status of smokers to be dependent if they fulfill two or more question.

1. Ever cut down the dose?

2. Felt annoyed when called as smoker?

3. Felt guilty?

4. Do you need it as an Eye opener?

Verbal consent was taken with each subject prior of the interview and the data collected were kept confidential. Datacollected was entered into MS Excel spread sheet, coded and analyzed using SPSS 11.5 version.

\section{RESULTS}

Socio-demography characteristics of the study population showed that majority of the study population belonged to the age group more than 36 years (Table.1). Male were found to be predominant smokers, about half of the study population were illiterate and almost 38\% were unemployed. Rajbanshi were the main ethnic group followed by Brahmin and Rai/limbu. More than $80 \%$ of the smokers fell below the poverty line.

Regarding the age of initiation of smoking and duration (about $63 \%$ of the smokers had started smoking at the age of 10 years and $79 \%$ of them were found to have smoked for more than 10 years. Similarly, majority of them smoked non-filter cigarette, bidi (tobacco wrapped in leaves) and almost half of them were found to be smoking 5 or more sticks per day whereas $4.5 \%$ of them smoked more than 20 sticks per day. This study revealed $38 \%$ of the smokers also had other family members who smoked. (Table 2)

Among the common reasons for initiation of smoking peer pressure was reported to be $43 \%$ followed by curiosity and imitating the actions of others respectively. Nearly $10 \%$ started for enjoyment and almost same proportion initiated for relieving thestress.In order to assess the dependency status of smoking, CAGE questionnaire was used. It showedthat, $68 \%$ of them were dependent smokers. (Table 3, 4)

Regarding the ill effects of smoking among the smokers, majority of them knew more than one type of health problems by smoking. The most common ill-health consequences due to smoking was reported to be lung cancer (40\%) followed by staining of teeth, heart disease, bronchitis and Tuberculosis. (Table 5)
Table1: Demographic characteristics of the Smokers $(n=200)$

\begin{tabular}{|c|c|c|}
\hline Characteristics & Frequency & $\%$ \\
\hline \multicolumn{3}{|l|}{ Age ( Years) } \\
\hline$<15$ & 1 & 0.5 \\
\hline $15-25$ & 22 & 11.0 \\
\hline $26-35$ & 29 & 14.5 \\
\hline $36-45$ & 40 & 20.0 \\
\hline $46-55$ & 33 & 16.5 \\
\hline$>55$ & 75 & 37.5 \\
\hline \multicolumn{3}{|l|}{ Gender } \\
\hline Male & 152 & 76.0 \\
\hline Female & 48 & 24.0 \\
\hline \multicolumn{3}{|l|}{ Educational status } \\
\hline Illiterate & 152 & 76.0 \\
\hline Literate & 48 & 24.0 \\
\hline \multicolumn{3}{|l|}{ Occupation } \\
\hline Unemployed & 75 & 37.5 \\
\hline Farmer & 62 & 31.0 \\
\hline Factory labor & 51 & 25.5 \\
\hline Small business & 8 & 4.0 \\
\hline Student & 4 & 2.0 \\
\hline \multicolumn{3}{|l|}{ Ethnicity } \\
\hline Rajbanshi & 85 & 42.5 \\
\hline Brahmin & 44 & 22.0 \\
\hline Kirat & 33 & 16.5 \\
\hline Muslim & 10 & 5.0 \\
\hline Other (Rishidev, sada, Mushar) & 19 & 9.5 \\
\hline Chhetri & 9 & 4.5 \\
\hline \multicolumn{3}{|l|}{ Socioeconomic status } \\
\hline Below Poverty Line $(<1.25 \$$ per day $)$ & 165 & 82.5 \\
\hline Above Poverty Line $(>1.25 \$$ per day) & 35 & 17.5 \\
\hline
\end{tabular}


Table 2: Distribution of smoking status of Study Subjects $(\mathrm{n}=\mathbf{2 0 0})$

\begin{tabular}{|c|c|c|}
\hline Characteristics & Frequency & Percentage \\
\hline \multicolumn{3}{|c|}{ Age of onset of smoking } \\
\hline$<10$ & 21 & 10.5 \\
\hline $10-19$ & 126 & 63.0 \\
\hline $20-29$ & 37 & 18.5 \\
\hline$\geq 30$ & 16 & 8.0 \\
\hline \multicolumn{3}{|c|}{ Duration of smoking } \\
\hline$<1 \mathrm{yrs}$ & 2 & 1.0 \\
\hline $1-5 y r s$ & 22 & 11.0 \\
\hline $6-10$ & 19 & 9.5 \\
\hline$\geq 10 \mathrm{yrs}$ & 157 & 78.5 \\
\hline \multicolumn{3}{|c|}{ Types of smoking sticks } \\
\hline Filter & 52 & 26.0 \\
\hline Non filter & 148 & 74.0 \\
\hline \multicolumn{3}{|c|}{ Number of Sticks per day } \\
\hline$<5$ & 102 & 51.0 \\
\hline$\geq 5$ & 98 & 49.0 \\
\hline \multicolumn{3}{|c|}{ Members in family smokes } \\
\hline Yes & 76 & 38.0 \\
\hline No & 124 & 62.0 \\
\hline
\end{tabular}

Table 3: Reason for starting cigarette of study population

\begin{tabular}{|l|l|l|}
\hline Characteristics & Frequency & Percentage * \\
\hline Company of friends & 86 & 43 \\
\hline Curiosity & 40 & 20 \\
\hline Imitate & 35 & 17.5 \\
\hline Enjoyment & 20 & 10 \\
\hline Relieve tension & 19 & 9.5 \\
\hline
\end{tabular}

*multiple responses
Table 4: CAGE criteria for assessment of dependency among the smokers $(n=200)$

\begin{tabular}{|l|l|l|}
\hline CAGE Score & Frequency & Percentage \\
\hline Yes $(\geq 2)$ & 136 & 68 \\
\hline No $(<2)$ & 64 & 32 \\
\hline
\end{tabular}

Table 5: Health Knowledge about smoking effects on health by smokers of study population

\begin{tabular}{|l|l|l|}
\hline Characteristics & Frequency & Percentage * \\
\hline Lungs cancer & 80 & 40.0 \\
\hline Staining of teeth & 70 & 35.0 \\
\hline Heart disease & 66 & 33.0 \\
\hline Bronchitis & 60 & 30.0 \\
\hline Tuberculosis & 50 & 25.0 \\
\hline Bleeding of gums & 46 & 23.0 \\
\hline Foul smells & 40 & 20.0 \\
\hline
\end{tabular}

* Multiple responses

\section{DISCUSSION}

In our study, the proportion of smoker was higher in age group after 35 years. It indicated that prevalence of smokers increased with increased age. This finding was consistent with many other finding. ${ }^{15,16,17}$ Male were predominant smoker in our study. This could probably be due to the shy nature of women who hesitated to participate in this survey. Rajbanshi and Brahmin were the main ethnic groups to be smoking in our study as majority of the participants were Rajbanshi and was consistent with the Village Development Committee Profile of Nepal. ${ }^{20}$ Majority of the smokers were unemployed and illiterate. Study done by Dieter Henkel $^{18}$ et al also reported, the proportion of unemployment could have been more due to increased addiction towards smoking and alcohol consumption. Four out of five smokers fell below the poverty line probably due to lack of employment. Study by Soteriades ES et al. also showed that the lowest-status occupational groups were twice likely to be smokers in compare to those in the higher status occupational group. ${ }^{19}$ Smoking among youth is associated with additional health and social problems. Smoking affects physical growth and youth activities. The more the people start to smoke at an early age , the more likely they are likely to be addicted to nicotine. Usually it's observed that, most smokers begin smoking during their transition to adulthood. ${ }^{21}$ Our study also reported; high proportion of smokers who initiated smoking at the age of 10-19 years which was also similar to the findings by Shreeramareddy CT et al and Karki YB et. al. ${ }^{11,17}$

Our study showed that half of them smoked five or more cigarettes per day. Similar result was observed in the study done 
in Nepal. ${ }^{16}$ Person having friends and family members who smoke were more likely to be ever smokers. Our study found that, about $38 \%$ family member of the smokers smoke. This was also observed by Leather dale ST et al where he mentioned that, smoking is influenced when there is smoker in their family and surroundings. ${ }^{22}$

It was also observed that, several other factors like pocket money, lack of supervision by parents were also found to be associated with smoking and promoted smoking in an early age. Friend circle was also reported to be an important for early initiation of smoking. Among the smokers, $68 \%$ of them were observed to have developed dependency towards tobacco or tobacco related products. In the study by OttC Het al, the majority of study population who smoked felt they had a problem with smoking when assessed with CAGE questionnaire and the CAGE score was higher among the smokers than in non-smokers. ${ }^{23}$ To our surprise, majority of the smokers were aware about the ill effects of smoking on health, even then they were smoking. Similar observation was reported in other studies. ${ }^{24}$

\section{CONCLUSION}

Majority of the smokers were male, illiterate and fell below the poverty line and had smoked for more than 10 years. They initiated smoking before the age of 20 years. Friends and family members who smoke were found to be common reasons for early initiation of smoking and it's dependency was noted among $68 \%$ of them.

The limitation of this study includes small sample size with low response rate. 200 respondents were taken purposively which on its own is a bias. Some of the participants were reluctant to answer and some were found to be influenced by the presence of family members or neighbors.

\section{ACKNOWLEDGEMENT}

I would deeply like to express my gratitude to the all the residents of Jalthal \& Maheshpur who helped us in data collection by their active participation. My sincere gratitude to all the colleagues of School of Public Health and Community Medicine, BP Koirala Institute of Health Sciences for the valuable time and cooperation. Similarly, my sincere regards to Palikhe A,Verma A, Koirala B,Vardhan H, Shah J, Gupta PK, Prasoon P, Jha PK, Das R, Shrestha S, Karn V) who shoed active participation during data collection.

\section{REFERENCES}

1. Tobacco frees Initiative (TFI), World Health Organization, 2004.

2. Tobacco control country profiles. Second edition, Atlanta, G.A American Cancer Society 2003.

3. Tobacco control country profiles. Second Edition, 2003: 10.

4. Mackay J, Eriksen M. The Tobacco Atlas. World Health Organization 2002.

5. ChollatTraquet CM. Women and Tobacco. Geneva, World Health Organization 1992:63-66.

6. World Health Organization: The impact of chronic diseases in Nepal. WHO 2002.

7. WHO South-East Asia Region: WHO World Health Survey. WHO Global InfoBase Version:1.292 beta 2001 .
8. Binu VS, Subba SH, Menezes RG, Kumar G, Ninan J, Rana MS et al. Smoking among Nepali youth-prevalence and predictors. Asian Pac J Cancer Prev 2010;11:221-226.

9. Niraula SR. Tobacco use among women in Dharan, eastern Nepal. J Health Popul Nutr 2004;22:68-74.

10. Sreeramareddy CT, Kishore P, Paudel J, Menezes RG. Prevalence and correlates of tobacco use amongst junior collegiates in twin cities of western Nepal: a cross-sectional, questionnaire-based survey. BMC PublicHealth 2008;8:97.

11. Sreeramareddy CT, Suri S, Menezes RG, Kumar HN, Rahman M, Islam MR et al. Self-reported tobacco smoking practices among medical students and their perceptions towards training about tobacco smoking inmedical curricula: A crosssectional, questionnaire survey in Malaysia,India, Pakistan, Nepal, and Bangladesh. Subst Abuse Treat Prev Policy 2010; 5:29.

12. Jha NP, Upadhyaya MP, Lakhey S, Yadav BK, Baral DD, Gautam A. Smoking and smokers in Sunsari, Nepal. J Nep Med Assoc 1999;38:7-13.

13. Shimkhada R, Peabody JW: Tobacco control in India. Bull World Health Organ 2003;81:48-52.

14. Bernat DH, Erickson DJ, Widome R, Perry CL, Forster JL. Adolescent smoking trajectories: results from a populationbased cohort study. J Adolesc Health 2008;43:334-40.

15. NDHS 2006. Population Division, Ministry of Health Government of Nepal, Kathmandu, Nepal, New ERA, Kathmandu, Nepal 2006.

16. Non Communicable Disease Risk Factors Survey. Kathmandu, 2008 SOLID Nepal, WHO Ministry of Health and Population, STEPS Surveillance.

17. Karki YB, Pant KD, Pande BR. The economics of tobacco in Nepal.HNP Discussion Paper. Economics of Tobacco Control Paper No 13. Washington DC: World Bank 2003.

18. Henkel D. Unemployment and Substance Use: A Review of the Literature (1990-2010), Current Drug Abuse Reviews 2011;4(1):4-27.

19. Soteriades ES, DiFranza JR. Parents socioeconomic status, adolescents' disposable income, and adolescents' smoking status in Massachusetts. Am J Public Health 2003;93:1155-60.

20. Village Development Committee Profile of Nepal: A SocioEconomic Development Database of Nepal. Intensive study and research center.

21. Willard JC, Schoenborn CA. Relationship between cigarette smoking and other unhealthy behaviors among our nation's youth: United States, 1992. Advance Data from Vital and Health Statistics 1995:263;1-11.

22. Leatherdale ST, Cameron R, Brown SK, Jolin AM, Kroeker $\mathrm{C}$. The influence of friends, family, and older peers on smoking among elementary school students: Low-risk students in highrisk schools. Preventive Medicine 2006;42:218-222.

23. Ott C H, Plach SK Hewitt JB, Cashin SE, Kelber S, Cisler RA, Weis J M. Smoking-Related Health Behaviors of Employees and Readiness to Quit. AAOHN Journal. 2005;53(6):249-256. 24. Nsereko E,Brysiewicz P, Mtshali NG. Knowledge and practice regarding smoking among staff members of a hospital in Kigali, Rwanda. PNT 2008;12(6):27-29. 